https://helda.helsinki.fi

\title{
Acute kidney injury in sepsis
}

\section{Bellomo, Rinaldo}

2017-06

Bellomo, R , Kellum , J A, Ronco , C , Wald , R, Martensson, J , Maiden , M , Bagshaw , S M , Glassford, N J , Lankadeva , Y , Vaara , S \& Schneider , A 2017 , ' Acute kidney injury in sepsis ' , Intensive Care Medicine , vol. 43 , no. 6 , pp. 816-828 . https://doi.org/10.1007/s00134-017-4755-7

http://hdl.handle.net/10138/237045

https://doi.org/10.1007/s00134-017-4755-7

unspecified

publishedVersion

Downloaded from Helda, University of Helsinki institutional repository.

This is an electronic reprint of the original article.

This reprint may differ from the original in pagination and typographic detail.

Please cite the original version. 


\title{
REVIEW
}

\section{Acute kidney injury in sepsis}

\author{
Rinaldo Bellomo ${ }^{1,2^{*}}$, John A. Kellum ${ }^{3}$, Claudio Ronco ${ }^{4,5}$, Ron Wald ${ }^{6,7}$, Johan Martensson ${ }^{8}$, Matthew Maiden ${ }^{9,10}$, \\ Sean M. Bagshaw ${ }^{11}$, Neil J. Glassford ${ }^{12,13}$, Yugeesh Lankadeva ${ }^{14}$, Suvi T. Vaara ${ }^{15}$ and Antoine Schneider ${ }^{16}$
}

๑) 2017 Springer-Verlag Berlin Heidelberg and ESICM

\begin{abstract}
Acute kidney injury (AKI) and sepsis carry consensus definitions. The simultaneous presence of both identifies septic AKI. Septic AKI is the most common AKI syndrome in ICU and accounts for approximately half of all such AKI. Its pathophysiology remains poorly understood, but animal models and lack of histological changes suggest that, at least initially, septic AKI may be a functional phenomenon with combined microvascular shunting and tubular cell stress. The diagnosis remains based on clinical assessment and measurement of urinary output and serum creatinine. However, multiple biomarkers and especially cell cycle arrest biomarkers are gaining acceptance. Prevention of septic AKI remains based on the treatment of sepsis and on early resuscitation. Such resuscitation relies on the judicious use of both fluids and vasoactive drugs. In particular, there is strong evidence that starch-containing fluids are nephrotoxic and decrease renal function and suggestive evidence that chloride-rich fluid may also adversely affect renal function. Vasoactive drugs have variable effects on renal function in septic AKI. At this time, norepinephrine is the dominant agent, but vasopressin may also have a role. Despite supportive therapies, renal function may be temporarily or completely lost. In such patients, renal replacement therapy (RRT) becomes necessary. The optimal intensity of this therapy has been established, while the timing of when to commence RRT is now a focus of investigation. If sepsis resolves, the majority of patients recover renal function. Yet, even a single episode of septic AKI is associated with increased subsequent risk of chronic kidney disease.
\end{abstract}

Keywords: Sepsis, Acute kidney injury, Biomarkers, Creatinine, Renal replacement therapy, Recovery

\section{Introduction}

Septic acute kidney injury (AKI) is a syndrome of acute impairment of function and organ damage linked with long-term adverse outcomes depending on the extent of acute injury superimposed on underlying organ reserve. Implicit in this concept is that dysfunction should be reversible and rescue is possible, but that duration of the insult and underlying renal reserve may limit restoration of renal function. Thus, septic AKI is a clinical diagnosis based on specific, context-dependent, and imperfect

\footnotetext{
*Correspondence: Rinaldo.bellomo@austin.org.au

${ }^{2}$ Department of Intensive Care, Austin Hospital, Heidelberg, VIC 3084, Australia

Full author information is available at the end of the article
}

Take-home message: Septic acute kidney injury is no longer considered a disease of the macrocirculation, but rather a disorder of the renal microcirculation with associated inflammatory tubular injury. These new ideas have profound diagnostic and therapeutic implications. definitions [1] with azotemia and oliguria still its key diagnostic criteria [2]. In this article, we aim to review recent developments and key aspects of the epidemiology, pathogenesis, prevention, and treatment of septic AKI with the goal of increasing understanding and awareness among clinicians of this increasingly common intensive care syndrome.

\section{Definition and diagnosis of septic AKI}

The RIFLE criteria (Risk Injury Failure Loss End-stage renal disease) were proposed by the Acute Dialysis Quality Initiative [1]. More recently, the Kidney Disease Improving Global Outcomes (KDIGO) group produced a unified version of all key criteria (Table 1) [2], which now represent global consensus. Similarly, a new global consensus definition of sepsis has emerged and is likely to be used for epidemiologic and clinical purposes [3]. Logically, septic AKI (or sepsis-associated AKI or AKI in

\section{至


Table 1 Criteria and staging for acute kidney injury

\begin{tabular}{lll}
\hline Stage & Serum creatinine & Urine output \\
\hline 1 & $1.5-1.9$ times baseline & $<0.5 \mathrm{ml} / \mathrm{kg} / \mathrm{h} \mathrm{for} 6-12 \mathrm{~h}$ \\
& OR & \\
& $\geq 0.3 \mathrm{mg} / \mathrm{dl}(>26.5 \mu \mathrm{mol} / \mathrm{l})$ increase & $<0.5 \mathrm{ml} / \mathrm{kg} / \mathrm{h} \mathrm{for} \geq 12 \mathrm{~h}$ \\
$2.0-2.9$ times baseline & $<0.3 \mathrm{ml} / \mathrm{kg} / \mathrm{h} \mathrm{for} \geq 24 \mathrm{~h}$ \\
3 & OR & OR \\
& Increase in serum creatinine to $\geq 4.0 \mathrm{mg} / \mathrm{dl}(353.6 \mu \mathrm{mol} / \mathrm{l})$ & Anuria for $\geq 12 \mathrm{~h}$ \\
& OR & \\
& Initiation of renal replacement therapy & \\
& OR & \\
& In patients $<18$ years, decrease in eGFR to $<35 \mathrm{ml} / \mathrm{min} \mathrm{per} 1.73 \mathrm{~m}^{2}$ &
\end{tabular}

Minimum criteria for acute kidney injury include an increase in SCr by $\geq 0.3 \mathrm{mg} / \mathrm{dl}$ ( $>26.5 \mu \mathrm{mol} / \mathrm{l})$ observed within $48 \mathrm{~h}$; or an increase in SCr to $\geq 1.5$ times baseline, which is known or presumed to have occurred within the prior 7 days; or urine volume $<0.5 \mathrm{ml} / \mathrm{kg} / \mathrm{h}$ for $6 \mathrm{~h}$

sepsis) should describe a syndrome characterized by the simultaneous presence of both Sepsis-3 and KDIGO criteria. Nonetheless, clinical judgment is still required [4], and a more modern framework for rapid clinical diagnosis is evolving which is based on novel biomarkers of renal injury (Table 2). Thus, future definitions of AKI may soon include such biomarkers. Irrespective of definition, knowledge of baseline renal function remains important and is needed to apply the KDIGO diagnostic criteria. Unfortunately, a baseline creatinine may not be available, and a patient with suspected septic AKI and unknown baseline function might have sepsis with chronic kidney disease (CKD), septic AKI, or both. Ancillary tests and checklists might be helpful to make the correct diagnosis [4]. In the absence of baseline information, however, an estimated GFR using the Modification of Diet in Renal Disease (MDRD) equation has been used in patients without a history of CKD (Table 2) [1]. Finally, although urinalysis and urinary biochemistry have limited clinical utility [5], urine output remains important not only for diagnosis but also for risk prediction [6]. However, urinary output and creatinine are increasingly being complemented by novel biomarkers of AKI.

\section{Novel biomarkers}

Over the last decade several biomarkers have been evaluated for their capacity to detect kidney "stress" and/or "damage" and to predict the development of AKI. They apply to septic AKI as well. The strong interest in biomarkers relates to the desire to achieve early diagnosis in order to deliver prevention and early therapy when it may be most effective. Biomarkers can provide additional insights into AKI pathophysiology and are complementary to functional tests [7]. These biomarkers might also detect renal stress or damage before functional change is evident (preclinical AKI) or even in the absence of functional change (subclinical AKI). In other cases, low biomarker levels may help diagnose physiologic in contrast with pathologic oliguria. Their role in different renal syndromes including septic AKI is a rapidly evolving area of research. Neutrophil gelatinase-associated lipocalin (NGAL) has been the most extensively investigated renal biomarker [8]. NGAL is upregulated in kidney tissue exposed to nephrotoxic or inflammatory stress, but also released by activated neutrophils with specific forms of the molecule released from the kidney (monomeric) and neutrophils (dimeric) [9]. Unfortunately, commercial assays only measure a mixture of the different forms making their specificity, reproducibility, and diagnostic accuracy unclear and creating uncertainty regarding the role of NGAL as a biomarker of AKI. In a pooled analysis of $>2000$ critically ill patients, one-fifth were NGAL-positive without an increase in serum creatinine (subclinical AKI or false positive results). Yet, these patients were at greater risk of subsequent renal replacement therapy (RRT), longer ICU and hospital stay, and death [10]. Similar findings were observed in emergency department patients [11] and support the existence of a state of subclinical damage, which is associated with worse renal outcomes, and can only be detected by novel biomarkers. Other molecules have been studied as biomarkers of AKI. Among these, kidney injury molecule (KIM-1) appears to perform similarly to NGAL [7] but has not been studied in a large cohort of septic ICU patients. Cell cycle arrest may be protective during cellular stress. Two major regulatory proteins involved in initiating cell cycle arrest were recently discovered to play a role in AKI: tissue inhibitor of metalloproteinases-2 (TIMP-2) and insulin-like growth factor binding protein-7 (IGFBP-7). In 2013, a prospective, observational, international investigation 


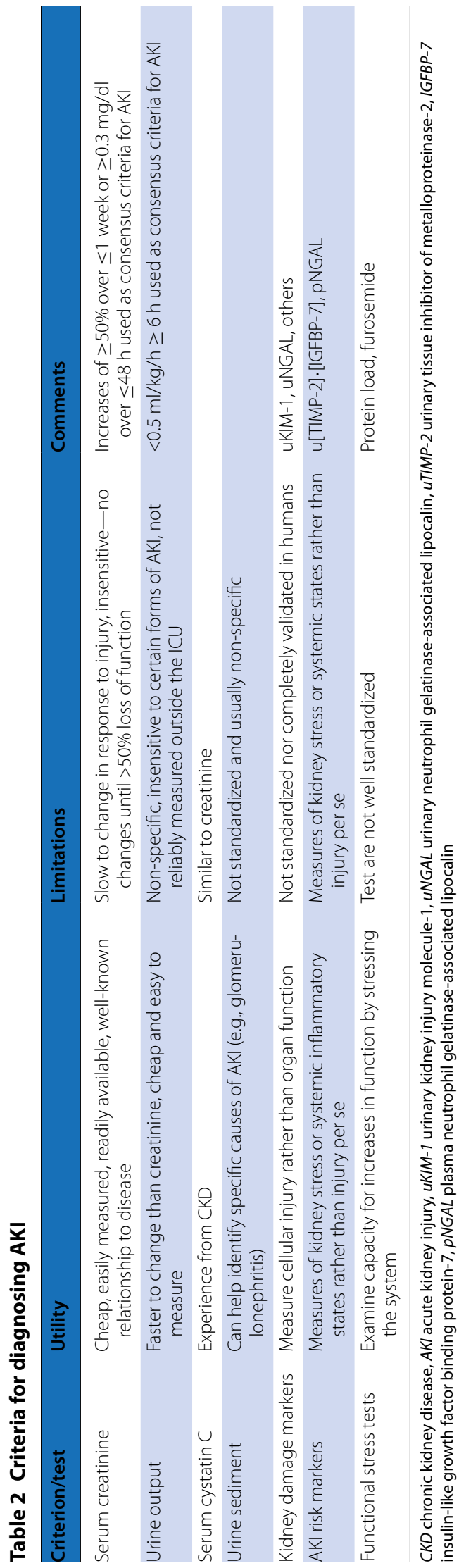

of critically ill patients, including many with septic AKI [12], found an area under the receiver operating characteristic curve (AUC) of 0.80 for [TIMP-2].[IGFBP-7] for the prediction of KDIGO stage 2 and 3 AKI. These markers were significantly superior to all previously described biomarkers. Moreover, tubular cells may undergo cell cycle arrest (as demonstrated by cell cycle arrest biomarkers in the urine) [12] to decrease energy consumption and protect themselves. This phenomenon may then result in activation of the tubulo-glomerular feedback mechanism [13], which would contribute to a decrease in GFR aimed at attenuating ultrafiltration. However, this theoretical framework, like others, remains speculative. These biomarkers may also help change the definition of AKI in the future and contribute to a better understanding, diagnosis, prevention, and treatment of septic AKI (Fig. 1). Other approaches to assess renal function have been considered. They include the furosemide stress test, and assessment of the response to protein loading [14] and the application of real-time GFR measurements [15]. None of these approaches have yet been tested for their accuracy and robustness in large multicenter studies and remain investigational in nature. However, there is no evidence at this time that knowledge of biomarker values in septic AKI allows better and more successful early treatment. Thus, current epidemiologic information remains linked to traditional diagnostic criteria.

\section{Epidemiology of septic AKI}

Several cohort studies have described the frequency of sepsis among patients with AKI. The multinational Beginning and Ending Supportive Therapy for the Kidney (BEST Kidney) [16] found sepsis in nearly half the cohort. Septic AKI was associated with higher risk of in-hospital mortality. More recently, an international consortium confirmed these findings [17]. Angus et al. examined 192,980 patients with severe sepsis from seven US states using diagnostic codes [18]. AKI occurred in 22\% and was associated with a mortality of $38.2 \%$. The Sepsis Occurring in Acutely ill Patients (SOAP) cohort study recruited patients admitted to 198 ICUs across Europe [19]. Of 3147 patients, $37 \%$ had sepsis. AKI occurred in $51 \%$ of cases and was associated with an ICU mortality of $41 \%$. The FINNAKI study enrolled 2901 critically ill consecutive patients from 17 Finnish ICUs [20]. Among the 918 patients with severe sepsis, 53\% met the KDIGO criteria for AKI. In the recent Vasopressin vs. Norepinephrine as Initial Therapy in Septic Shock (VANISH) trial, AKI occurred in about $45 \%$ of patients, and AKI requiring RRT developed in $30 \%$ of patients [21].

There may also be genetic susceptibility to AKI in general and to septic AKI specifically. Polymorphism of cytokine-controlling genes has been associated with 


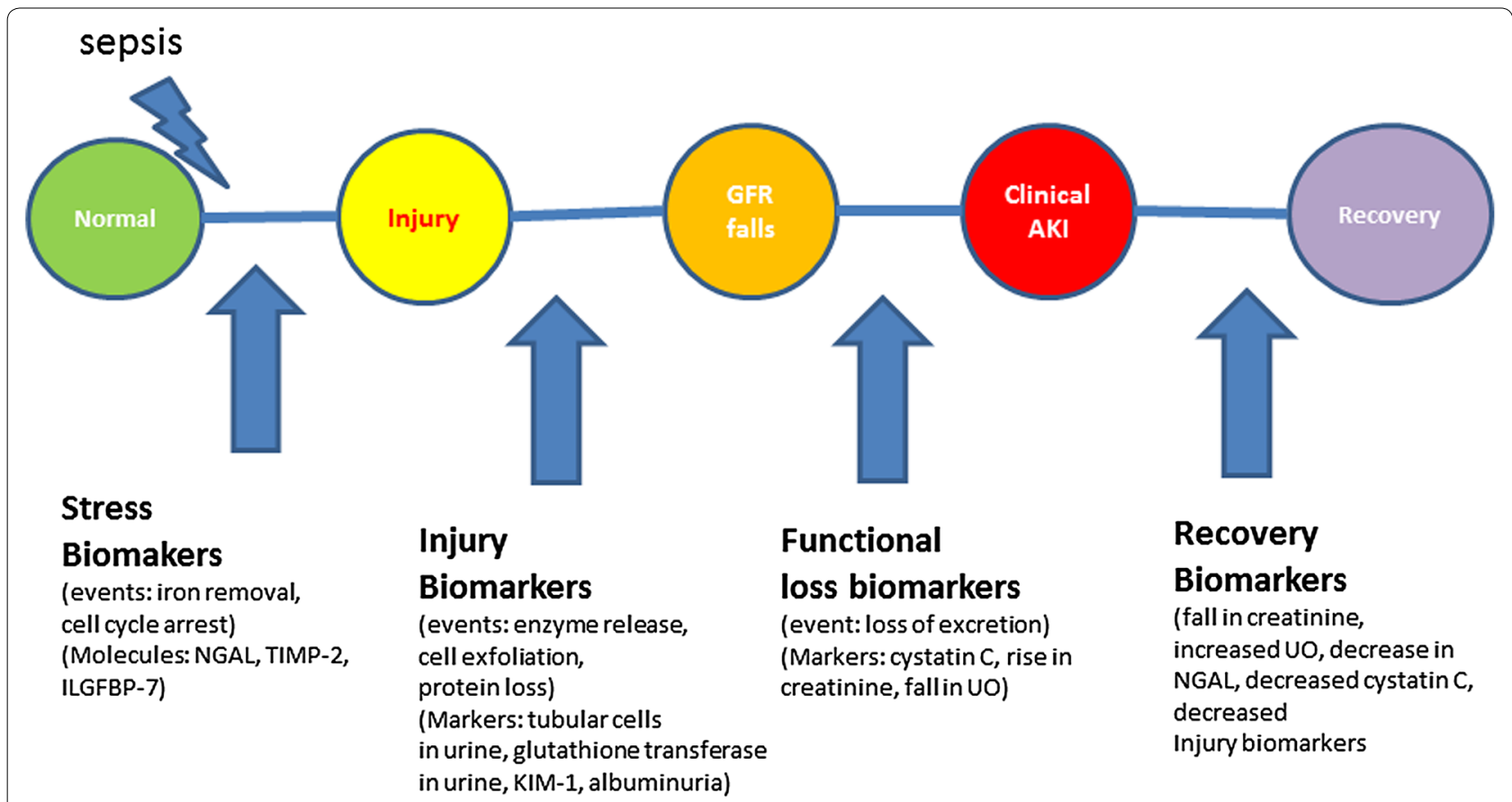

*NGAL: neutrophil gelatinase associated lipocalin; TIMP: tissue inhibitor of metallo-proteinase; ILGFBP: insulin like growth factor binding protein KIM: kidney injury molecule; UO: urinary output

Fig. 1 Potential contribution of novel renal injury biomarkers to the detection, prevention, and treatment of septic AKI

sepsis and polymorphism of catechol-O-methyl transferase activity has been associated with AKI risk [22]. More recently a genome-wide association study of patients with AKI (including septic AKI) found that polymorphism of the likely controller of a transcription factor (on chromosome 4) involved in innate immunity pathways was associated with greater risk of AKI. Similarly, another gene involved in the likely control of transforming growth factor beta (on chromosome 22) was also associated with greater risk [23].

The outcomes of critically ill patients with sepsis [24] and AKI requiring RRT [25], however, have improved in recent years. It remains unclear if these improvement reflect a true decline in mortality or greater diagnostic sensitivity or more liberal indications to initiate RRT. Moreover, little is known about AKI in septic general ward patients. The advent of the Sepsis-3 definitions will force a reassessment of the characteristics and outcomes of sepsis-associated AKI. However, such assessment must logically be based on an understanding of its pathophysiology.

\section{Pathophysiologic theories}

Our understanding of the pathogenesis of septic AKI is limited, but it is now clear that septic AKI is profoundly different from ischemic AKI both in the experimental setting and in the clinic. It is markedly affected by our inability to monitor renal blood flow (RBF), microvascular flow, cortical and medullary perfusion and oxygenation, and tubular well-being. Thus, animal models of septic AKI have been developed to enable sophisticated and invasive measurements that cannot be performed in humans. In early experimental studies of septic AKI, global RBF was reported to decline after the administration of endotoxin [26]. These endotoxin-based experiments, which were associated with a hypodynamic systemic circulation, led to the view that human septic AKI must be due to renal vasoconstriction and ischemia [26]. More recent studies of hyperdynamic sepsis have demonstrated that the renal circulation participates in the systemic vasodilatation of sepsis. Thus, in such models, septic AKI develops in the presence of increased RBF $[27,28]$.

In a study of 160 original articles of animal models [29], if the model reported a high cardiac output (CO), RBF was either preserved or increased. However, despite such global renal hyperemia, oliguria and AKI develop rapidly (hours) and are marked. This phenomenon, where RBF is dissociated from glomerular filtration rate (GFR), requires explanation. Changes in intrarenal 
hemodynamic (microvasculature) may logically provide such an explanation. For example, GFR may be decreased by changes in the relationship between the afferent and efferent glomerular arterioles, with greater efferent than afferent dilatation leading to loss of intraglomerular filtration pressure. This theory offers an explanation for the dissociation between perfusion and function in septic AKI (a phenomenon also seen in man [30]) but remains empirically untested. In this regard, the renal microcirculation may be a key area in determining function, injury, and recovery as it lies at the interface of endothelial and immune cells. In the most vascular organ in the body, it appears logical that it should be fundamental to both function and dysfunction [31].

Despite increased RBF, ischemia may still occur. More recent experimental evidence supports the view that in septic AKI, there is redistribution of flow away from the renal medulla to the renal cortex with a degree of medullary deoxygenation [32-34]. This change in regional distribution of blood flow implies the activation of intrarenal shunting pathways [35].

There is also limited systematic information on the renal tubules in sepsis, while GFR may be lost as described above. A pathophysiological theory of tubular injury has suggested that ultrafiltration of toxic blood is the inciting mechanism for tubular stress and then damage [13]. According to this theory, during sepsis, blood is full of small and medium-sized molecules (cytokines, chemokines, complement fragments, and the like), which have a toxic effect on tubular cells when concentrated in the ultrafiltrate acting on the luminal surface of the tubules [13]. This "inflammatory theory of AKI" is supported by experimental observations [36]. For example, pathogen-associated molecular patterns such as lipopolysaccharide can interact with Toll-like receptors (TLR) on tubular cells, and experimental studies have shown that the administration of TLR antagonists can attenuate septic AKI [36]. Moreover renal endothelial and tubular cells both express cytokine receptors and release pro-inflammatory molecules which can recruit $\mathrm{T}$ cells to the kidney and blood from septic patients can induce tubular cell apoptosis in vitro [36]. Thus, one of the renal responses to inflammation may be directed to decreased energy consumption with autodigestion of organelles (autophagy), digestion and dysfunction of mitochondria (mitophagy), and loss of cell polarity [37]. How these complex inflammatory events, which now include the release of histones, microparticles, and micro RNA, affect renal function remains unknown [36].

However, many of the above theories are based on animal models of sepsis and do not fully address the microscopic anatomical changes that might occur in renal tissue.

\section{Animal models and histopathology}

Most early in vivo models of septic AKI do not replicate the typical hyperdynamic state seen in man [38]. Moreover, models of renal ischemia are not relevant to the pathophysiology of septic AKI. Sheep, however, develop a cardiovascular response to sepsis similar to humans, and they have been used extensively to study septic AKI using live Gram negative bacteria infusions which overcome the flaws of endotoxin-based models [28, 33]. However, the choice of bacteria, strain, amount, and infusion rate can alter the septic response and standardization is difficult. Polymicrobial abdominal sepsis can be induced by cecal ligation and puncture (CLP), bowel ischemia, or intra-abdominal implantation of feces. These methods of inducing sepsis are relatively easy, but the amount and type of bacteria released are variable with a variable severity of sepsis that does not consistently lead to AKI. Clinicians need to understand these factors when interpreting data acquired from models including renal histopathology.

Structural lesions of the kidney have been thought to contribute to the renal dysfunction of septic AKI. In particular, acute tubular necrosis (ATN) is assumed to account for such dysfunction. However, in human septic AKI postmortem studies, ATN is uncommon [39, 40]. Similarly, ATN is uncommon in experimental septic AKI [41]. Moreover, ATN may not be a useful term because it lacks a clear definition, is not quantifiable, and does not account for the functional changes seen during sepsis. In this regard, studies have compared the histology of postmortem renal tissue of those who died with and without sepsis. They found more minor tubular lesions, leucocyte infiltration, and apoptosis in septic kidneys [39, 40]. These changes were only focal, most nephrons appeared normal, and indices of renal dysfunction poorly predicted renal histological changes. Thus, like RBF, histology appears dissociated from function. The picture is further clouded by the sampling of tissue from patients dying following variable severity of renal dysfunction, premorbid renal disease, therapeutic interventions, nephrotoxin exposure, and severity of illness.

Recently, a controlled experimental study of septic AKI in sheep concurrently monitored renal function, renal blood flow, obtained sequential renal biopsies over $48 \mathrm{~h}$, and undertook systematic histological assessment [42]. As severe septic AKI developed, RBF and renal oxygen consumption were unchanged and the only histological abnormality was minor focal mesangial expansion on electron microscopy. Thus, there is a disconnect between function and structure in septic AKI, and the early changes in renal function with sepsis appear to primarily represent a functional rather than structural disease. If it is true that early (first 24-48 h) septic AKI represents 
functional changes in the microvasculature and tubules, then early intervention and prevention of progression acquire great importance.

\section{Prevention}

There is a strong rationale to prevent the occurrence of AKI. The first priority for prevention is the identification of patients at increased risk. Such information is crucial to the development of a prevention and treatment plan (Fig. 2). Recent evidence has focused on clinical risk prediction [43], novel kidney damage biomarkers [44], automated electronic alerts embedded within electronic health records [45], and the concept of the renal angina index (RAI) [46]. Moreover, adaptive risk identification tools can be developed for adult critically ill patients, integrating known susceptibilities (i.e., age, diabetes mellitus, heart failure, chronic kidney disease, liver disease, malignancy) and other potentially modifiable factors (i.e., urine output, fluid balance). Such tools could be integrated into an ICU bedside clinical decision support system [47]. Risk identification tools can now be used in combination with novel kidney damage urine biomarkers [7]. Recent data have suggested that urine TIMP2-IGFBP-7 significantly improved risk prediction when added to a nine-parameter clinical model [48].

To date, implementation of automated alerts for AKI has not been shown to consistently improve processes of care or outcomes. However, in an ICU setting, among patients who had an automated alert issued for AKI, more interventions were given (i.e., diuretics, fluid, vasopressors); time to intervention was shortened and a greater proportion recovered kidney function to baseline [45]. Patients at increased risk should have appropriate adjustment, discontinuation, or avoidance of nephrotoxins, including unnecessary exposure to contrast media. Beyond such seemingly obvious interventions, only a limited number of preventive treatments are potentially available.

\section{Antibiotics and source control}

Earlier and appropriate antimicrobial therapy, along with septic source control, has been associated with lower risk of AKI [49]. For each hour that appropriate antimicrobial therapy was delayed, the risk of AKI increased by approximately $40 \%$. Moreover, earlier antimicrobial therapy was associated with greater likelihood of kidney recovery within $24 \mathrm{~h}$ [49]. Finally, experimental studies focused on immune modulation and microcirculatory performance have characterized a number of possible new interventions. None, however, have yet been tested in robust clinical trials.

\section{Hemodynamic optimization}

Early goal-directed therapy (EGDT) failed to show benefit for reducing AKI, utilization of RRT, or kidney recovery [50]. The ProMISe [51], ProCESS [52], and ARISE trials [53] demonstrated no difference in mortality or improved renal outcomes with EGDT. However, post hoc analysis from a multicenter trial suggested, among patients with mild AKI, that addition of low-dose vasopressin

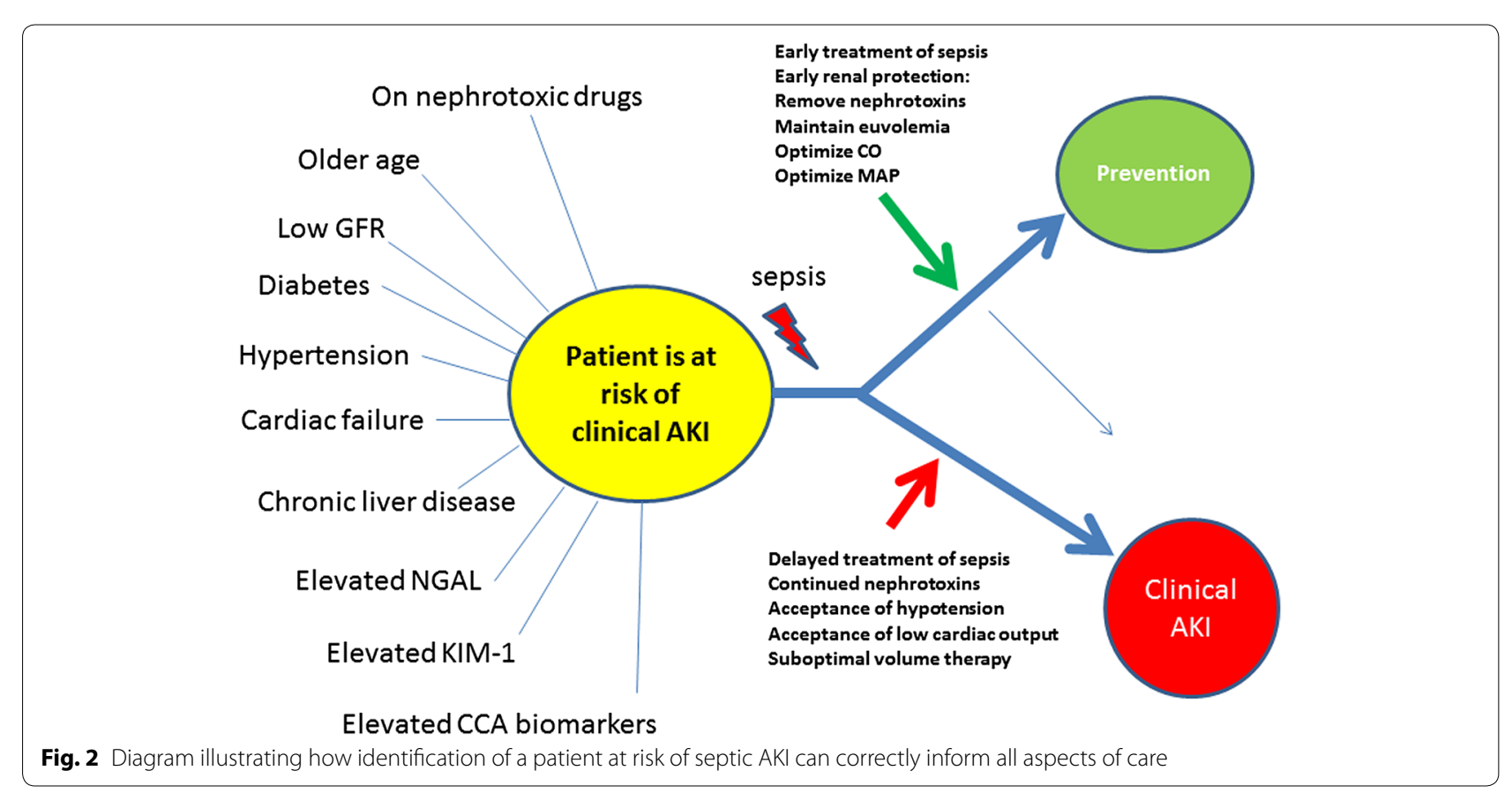


to norepinephrine infusion for hemodynamic support in septic shock was associated with reduced likelihood of worsening AKI, receipt of RRT, and mortality [54]. Recently, the VANISH trial found no significant differences in the rate of stage $3 \mathrm{AKI}$ or kidney injury-free days among 409 septic shock patients randomized to either vasopressin or norepinephrine as initial vasopressor [21]. Fenoldopam, a selective dopamine receptor-1 agonist, was found to reduce the number of patients who reached a serum creatinine greater than $150 \mu \mathrm{mol} / \mathrm{l}$ in a randomized trial of 300 septic critically ill patients; however, this effect did not translate into decreased mortality [55] and has not yet been confirmed in subsequent studies.

\section{Fluids}

Traditional teaching suggests that aggressive fluid therapy is crucial to the successful management of both sepsis and AKI. However, as discussed above, septic AKI may not be characterized by hypoperfusion. Thus, aggressive fluid administration may be physiologically illogical and ineffective; it may contribute to renal edema which, in an encapsulated organ, may induce congestion and ischemia (Fig. 3).

Fluid bolus therapy (FBT), combined with the oliguria of AKI, is likely to lead to fluid accumulation in septic patients [56]. Fluid accumulation was associated with adverse outcomes and increased mortality from the Vasopressin versus Norepinephrine Infusion in Patients with Septic Shock [57] and in the Fluids and Catheters Treatment [58] trials, and in the Program to Improve Care in Acute Renal Disease group [59], with persistent and pervasive data demonstrating harm in a variety of patient populations including those with septic AKI. In contrast, the pilot Conservative vs. Liberal Approach to fluid therapy of Septic Shock in Intensive Care (CLASSIC) trial demonstrated that restricting resuscitation volumes in patients with septic shock is feasible and may improve renal outcomes [60]. In the CLASSIC study, a

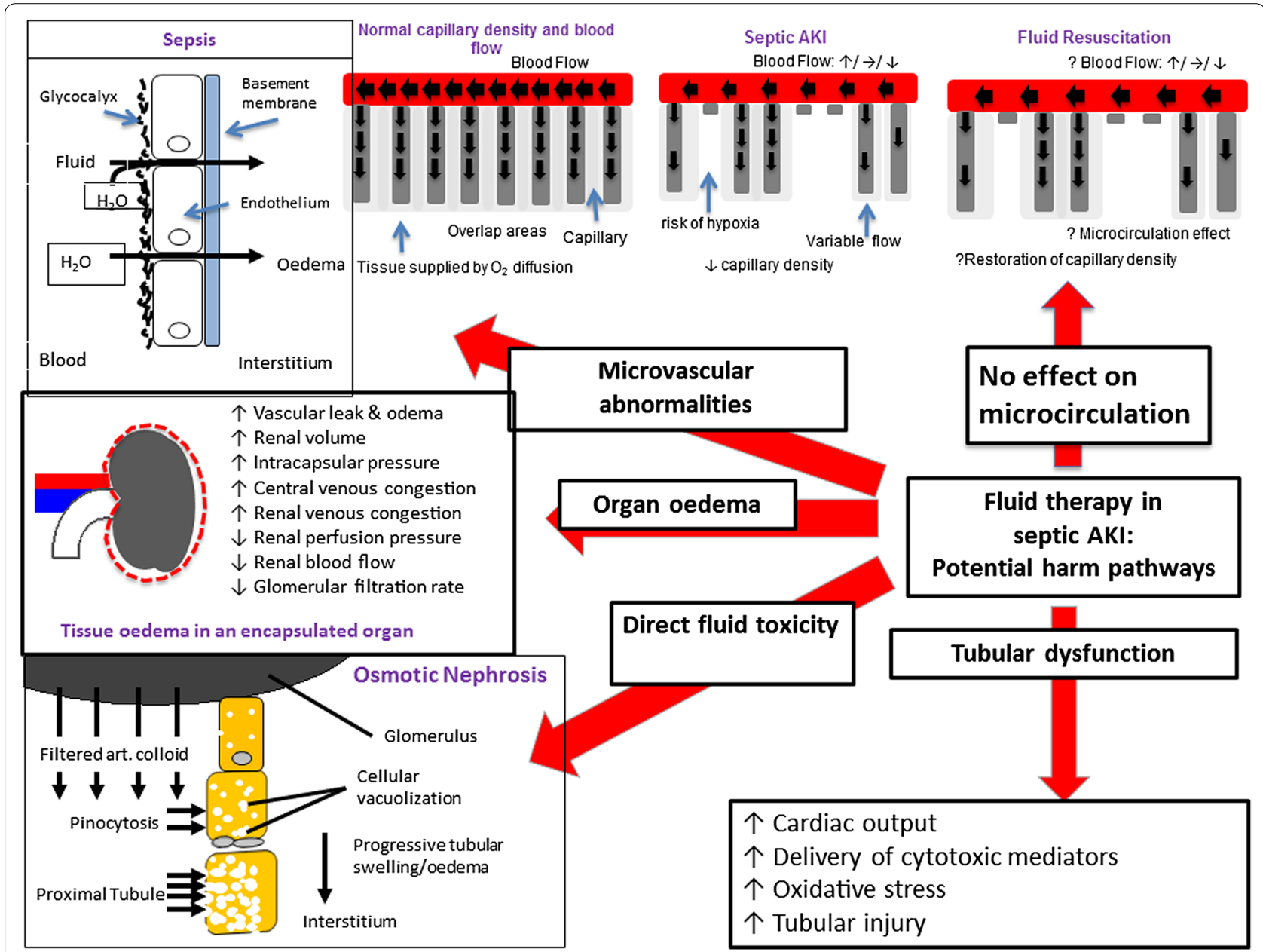

Fig. 3 Illustration of possible injury pathways that might be associated with overzealous fluid resuscitation in patients at risk of or developing septic AKI (interpretation of data from references [29-32]) 
pilot assessment of more restrictive fluid therapy, AKI was more likely to worsen in patients receiving standard care (restrictive: $37 \%$ vs. standard: $54 \%, P=0.03$ ). Other recent studies have shown lack of effect of FBT on renal function or urinary output [61-63].

\section{Fluid type}

A preference for balanced crystalloid solutions is emerging, with observational evidence linking chloride loading with AKI and mortality $[64,65]$. However, a recent multicenter, cluster-randomized, double-crossover randomized controlled trial (RCT) demonstrated no such toxicity in an undifferentiated population of critically ill patients or, on subgroup analysis, in those with sepsis $(n=84)$ [66]. However, in such a study the amount of trial fluid administered was limited, making assessment of an effect problematic. In a prospective, open-label, cluster-randomized, multiple-crossover trial comparing the use of saline and balanced crystalloids in a single medical ICU where the type of fluid administered alternated monthly after random allocation, no difference was seen between groups in the rate of major adverse kidney events at 30 days. However, on analysis of the 260 patients with sepsis, balanced solution led to a significant reduction in the risk of the composite outcome (odds ratio 0.56) [67]. These variable effects may be related to the dose of exposure to exogenous chloride.

While $4 \%$ albumin does not appear injurious to the kidney [68], artificial colloids have been demonstrated to be nephrotoxic. Hydroxyethyl starch [69] and gelatin solutions [70] have been associated with an increased risk of AKI in septic patients and an increased risk of mortality in patients with septic AKI. Given the lack of a survival advantage, the risks associated with their use, their accumulation in tubular cells (Fig. 3), and their elevated cost in comparison to crystalloid solutions, it is difficult to see a role for artificial colloids in the modern management of septic AKI. In contrast, in many patients with septic AKI, another key intervention, often combined with fluid therapy and perhaps more physiologically rational, is the use of vasoactive drugs.

\section{Vasoactive drugs}

In patients with sepsis-induced AKI, vasoactive drugs remain the cornerstone of hypotension management and can restore adequate organ perfusion pressure [71, 72]. The most commonly used vasoactive drugs are norepinephrine, epinephrine, vasopressin, dopamine, and phenylephrine. However, new evidence from clinical and experimental studies suggests that angiotensin II may also be effective in septic shock [71]. In the setting of septic AKI, it is unclear whether any one vasopressor drug confers better renal protection than another.
Nevertheless, norepinephrine can restore blood pressure and transiently improve renal function, with fewer side effects than alpha dose dopamine [73].

However, recent studies suggest that tissue ischemia and hypoxia may occur in the medulla, but not the cortex, before the development of septic AKI [34]. In such experimental models, restoring blood pressure with norepinephrine further exacerbates the degree of medullary ischemia and hypoxia (Fig. 4) [34]. These intrarenal changes occur independently of changes in global RBF and oxygen delivery and suggest that, while treatment with norepinephrine has beneficial effects on the systemic circulation and transiently increases renal function, it may also enhance medullary hypoxia and lead to long-term injury. These results suggest the need to carefully study different types of vasopressor drugs with or without fluid therapy in order to better define the optimal approach to preserving medullary oxygenation. Further studies of the renal microcirculation in septic AKI are therefore required to determine the causes of the reduced medullary perfusion and the effects of the subsequent medullary hypoxia. At this time, it is unclear whether norepinephrine-induced changes of medullary perfusion carry clinical implications and consequences. However, identifying whether vasoactive drugs, other than norepinephrine, have the potential to preserve, or even improve, regional kidney oxygenation and perhaps modify the shunting that is likely to take place in septic AKI appears important. However, not only the type of vasoactive agent but also the target mean arterial pressure may be important. In this regards, increasing mean arterial pressure to levels above $80 \mathrm{mmHg}$ with greater norepinephrine dosage [74] appears to have potential beneficial effects on renal function in patients with premorbid hypertension. If these hemodynamic interventions fail, clinicians are then faced with the need to consider RRT.

\section{Renal replacement therapy}

A proportion of septic patients ultimately receive RRT due to severe AKI. However, very few RCTs [75-78] of RRT (excluding reports related to immunomodulation) have included only septic patients (Table 3 ). Nonetheless, in septic AKI patients timing, dose, and modality are key RRT-related issues. When assessing the timing of RRT, one should consider both the phase of sepsis and AKI. Commencing RRT early in the disease process of both sepsis and AKI could improve outcomes by limiting fluid overload, organ injury, and by removing inflammatory mediators. However, it may also expose patients to inadequate dosing of antibiotics and the adverse effects of an extracorporeal circuit. An RCT of non-oliguric severe sepsis patients with mean baseline creatinine 

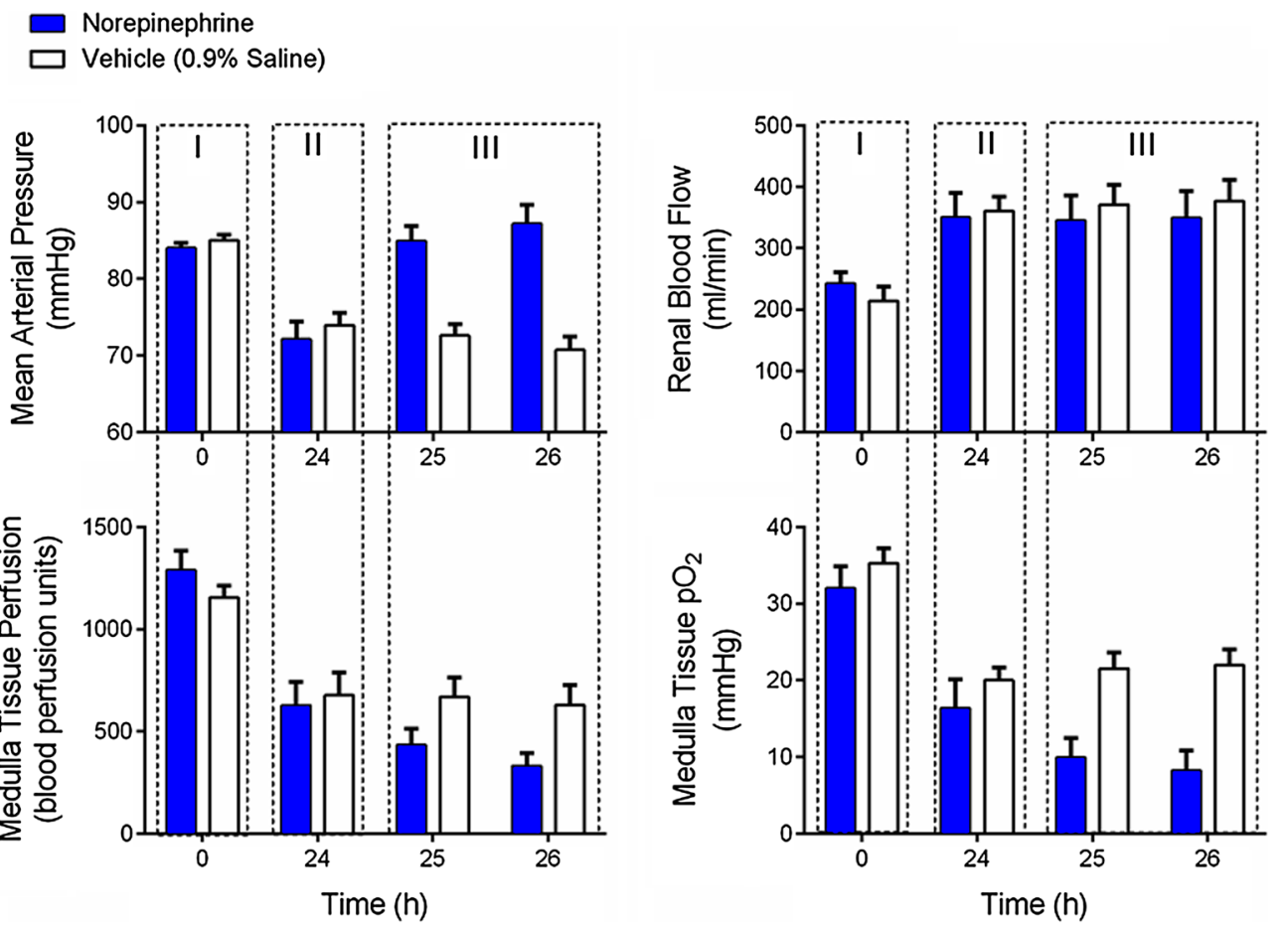

Fig. 4 Histograms summarizing the effects of norepinephrine in an experimental model of septic acute kidney injury in sheep using data from reference [34]. Even though mean arterial blood pressure and global renal blood flow increase, medullary perfusion and oxygenation decrease. Phase I indicates baseline, phase /l indicates infusion, phase III indicates post infusion status

around $190 \mu \mathrm{mol} / \mathrm{l}$ (suggestive of KDIGO stage $2 \mathrm{AKI}$ ) found that early RRT increased the degree of organ failures [75].

In contrast, a single-center RCT among mainly surgical patients found that early RRT improved survival [79]. A third RCT with almost $80 \%$ septic patients found no difference in survival between early and delayed RRT [80]. These differences reflected variation in design, population, and choice of RRT modality. Two much larger RCTs studying the timing of RRT are underway, one among septic patients (IDEAL-ICU, NCT01682590) and one among mixed septic and non-septic ICU patients (STARRT-AKI, NCT02568722).

Once a decision is made to start RRT, continuous RRT modalities are more frequently used and recommended for hemodynamically unstable patients. However, there is no clear evidence that choice of modality alters outcome in this patient population. Subgroup analyses among septic patients in the RENAL [81] and ATN [82] trials also found no significant difference between different levels of treatment intensity. Subsequent trials investigating high-volume hemofiltration among septic patients have failed to show any benefit (Table 3). Thus, a delivered dose of $20-25 \mathrm{ml} / \mathrm{kg} / \mathrm{h}$ is recommended. Notably, in a substudy of the RENAL trial, a quarter of patients receiving CRRT were outside target antibiotic concentrations regardless of continuous RRT dose, highlighting the need for improving the prescribing and monitoring of antibiotic levels during RRT [83]. Once septic patients have developed severe AKI and RRT is started a remaining key issue is that of prognosis and recovery.

\section{Clinical implications of trials}

Available trials as described above provide clinicians with several reference points which can then be applied and adjusted to individual situations in patients with or at risk of septic AKI. They indicate that early goal-directed therapy is not beneficial to renal function, that aggressive fluid loading with a positive fluid balance is not beneficial to renal function and may be injurious, and that artificial colloids are injurious to the kidney but that $4 \%$ albumin is not as shown in the SAFE and $20 \%$ is also safe as shown in the ALBIOS study [84]. They suggest that balanced solution may be safer than saline. They suggest that in patients with a history of hypertension, a higher blood pressure may protect renal function and that achieving blood pressure targets with the addition of vasopressin may improve renal function compared with norepinephrine alone. Moreover, they indicate that RRT intensity of $20-25 \mathrm{ml} / \mathrm{kg} / \mathrm{h}$ of solute clearance is the current standard of practice. However, the optimal timing and cessation of such RRT remain uncertain. 


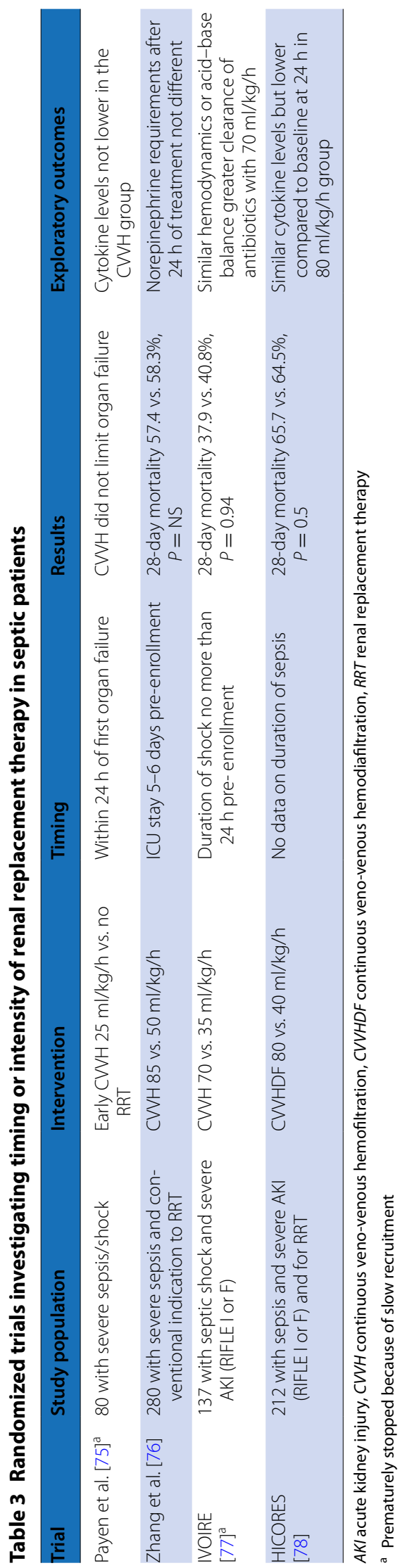

Ongoing phase II trials dealing with the potential value of alkaline phosphatase to protect the kidney from inflammation [85], and phase III trials dealing with the potential value of angiotensin II [86] as a vasopressor agent in sepsis and addressing the issue of timing of RRT (STARRT-AKI, NCT02568722) will likely provide more level 1 information to assist clinicians with their decisions.

\section{Prognosis of septic AKI}

Compared with other AKI etiologies, septic AKI may have specific prognostic implications. In most reports, it is associated with a higher short-term mortality rate. In a subgroup analysis of the BEST Kidney trial [16], the odds of dying in hospital were $50 \%$ higher in septic AKI compared with non-septic AKI. Obviously, the different prognosis between septic and non-septic AKI is largely influenced by the composition of the non-septic group and its proportion of conditions with poor prognosis (such as cardiogenic shock). In addition, the role of confounding in the association between septic AKI and mortality needs to be addressed as all studies consistently report higher illness severity at onset and more frequent need for RRT in such patients.

In contrast, for those patients who survive to hospital discharge, septic AKI has been associated with improved renal recovery compared with other AKI etiologies. In the BEST Kidney study [16] there was a trend for a lower serum creatinine and RRT dependence (9 vs. $14 \%, P=0.052)$. Obviously, numerous other factors are likely to play a role in renal recovery such as RRT modality, timing of RRT, and further nephrotoxic or ischemic insults. Renal recovery is also highly influenced by premorbid conditions as illustrated by a French multicentric observational study, which suggested that diabetic patients with septic AKI who survived to hospital discharge were more likely to require long-term RRT and had higher serum creatinine levels [87]. Irrespective of short-term recovery, however, it is now clear that even a single episode of AKI is associated with a greater risk of subsequent CKD and even end-stage kidney disease [88].

\section{Conclusions}

In critically ill patients, AKI is a common complication of sepsis, and sepsis is the most common trigger of AKI. Consensus criteria for both sepsis and AKI now exist and can be used to more clearly define its epidemiology. However, the development of novel biomarkers of AKI may soon lead to modifications in the definition of septic AKI. Irrespective of its epidemiology, our understanding of its pathophysiology remains limited and mostly based on animal models. Such models suggest that, at least in the first $24-48 \mathrm{~h}$, septic AKI may be a unique form of 
AKI with increased RBF, intrarenal shunting, and limited histological changes. Partly because of this limited understanding, our ability to prevent and treat septic AKI is also limited. In this regard, reliance on aggressive fluid-based therapy may be unwarranted and perhaps injurious. The use of vasoactive drugs to support blood pressure is warranted, but blood pressure targets may depend on premorbid blood pressure. If renal protection fails and RRT becomes necessary, the best timing and modality of such intervention remain uncertain. In contrast, dose of RRT is currently robustly based on findings from two large trials. If patients survive sepsis, recovery occurs in the majority, but our understanding of the mechanisms behind renal repair or failed renal repair remains poor and the lifetime risk of CKD and end-stage kidney disease is higher. Finally, the research agenda remains large, as recently reviewed [89], and should be a major focus for all clinicians dedicated to improved outcomes in this field.

\begin{abstract}
Author details
${ }^{1}$ School of Medicine, The University of Melbourne, Melbourne, Australia. 2 Department of Intensive Care, Austin Hospital, Heidelberg, VIC 3084, Australia. ${ }^{3}$ Department of Critical Care Medicine, Center for Critical Care Nephrology, University of Pittsburgh, Pittsburgh, USA. ${ }^{4}$ Department of Nephrology, Dialysis and Transplantation, San Bortolo Hospital, Vicenza, Italy. ${ }^{5}$ International Renal Research Institute of Vicenza (IRRIV) San Bortolo Hospital, Vicenza, Italy. ${ }^{6}$ Division of Nephrology, St. Michael's Hospital and the University of Toronto, Toronto, Canada. ${ }^{7}$ Li Ka Shing Knowledge Institute of St. Michael's Hospital, Toronto, Canada. ${ }^{8}$ Section of Anaesthesia and Intensive Care Medicine, Department of Physiology and Pharmacology, Karolinska Institutet, Stockholm, Sweden. ${ }^{9}$ Department of Intensive Care, Geelong University Hospital, Geelong, VIC, Australia. ${ }^{10}$ Department of Intensive Care, Royal Adelaide Hospital, Adelaide, SA, Australia. ${ }^{11}$ Department of Critical Care Medicine, Faculty of Medicine and Dentistry, University of Alberta, Edmonton, Canada. ${ }^{12}$ Department of Intensive Care, Austin Hospital, Melbourne, Australia. ${ }^{13}$ Department of Epidemiology and Preventive Medicine, Australian and New Zealand Intensive Care Research Centre, Monash University, Melbourne, Australia. ${ }^{14}$ Florey Institute of Neuroscience and Mental Health, Melbourne, VIC, Australia. ${ }^{15}$ Division of Intensive Care Medicine, Department of Anesthesiology, Intensive Care and Pain Medicine, University of Helsinki and Helsinki University Hospital, Helsinki, Finland. ${ }^{16}$ Adult Intensive Care Unit, Centre Hospitalier Universitaire Vaudois (CHUV), Lausanne, Switzerland.
\end{abstract}

\section{Compliance with ethical standards}

\section{Conflicts of interest}

Dr. Kellum and Dr. Ronco have received grants and consultation fees from Astute. Dr. Bellomo has received grants from Baxter and Braun.

Received: 18 December 2016 Accepted: 2 March 2017

Published online: 31 March 2017

\section{References}

1. KDIGO AKI Writing Group (2012) Kidney Disease: Improving Global Outcomes (KDIGO) clinical practice guideline for acute kidney injury. Kidney Int 2(Suppl. 2):1-141

2. Bellomo R, Ronco C, Kellum JA, Mehta RL, Palevsky P, Acute Dialysis Quality Initiative Workgroup (2004) Acute renal failure-definition, outcome measures, animal models, fluid therapy and information technology needs: the second international consensus conference of the acute dialysis quality initiative (ADQI) Group. Crit Care 8:R204-R212

3. Singer M, Deutschman CS, Seymour CW et al (2016) The third international consensus definitions for sepsis and septic shock (Sepsis-3). JAMA 315:801-810

4. Kellum JA, Bellomo R, Ronco C (2016) Does this patient have acute kidney injury? An AKI checklist. Intensive Care Med 42:96-99

5. Bagshaw SM, Bennett M, Devarajan P, Bellomo R (2013) Urine biochemistry in septic and non-septic acute kidney injury: a prospective observational study. J Crit Care 28:371-378

6. Kellum JA, Sileanu FE, Murugan R, Lucko N, Shaw AD, Clermont G (2015) Classifying AKI by urine output versus serum creatinine level. J Am Soc Nephrol 26:2231-2238

7. McCullough PA, Sahw AD, Haase M et al (2013) Diagnosis of acute kidney injury using funcitonal and injury biomarkers: workgroup statements from the tenth acute dialysis quality initiative consensus conference. Contrib Nephrol 182:13-29

8. Mårtensson J, Bellomo R (2014) The rise and fall of NGAL in acute kidney injury. Blood Purif 37:304-310

9. Mårtensson J, Xu S, Bell M, Martling CR, Venge P (2012) Immunoassays distinguishing between HNL/NGAL released in urine from kidney epithelial cells and neutrophils. Clin Chim Acta 413:1661-1667

10. Haase M, Devarajan P, Haase-Fielitz A, Bellomo R, Cruz DN, Wagener G, Krawczeski CD, Koyner JL, Murray P, Zappitelli M, Goldstein SL, Makris K, Ronco C, Mårtensson J, Martling CR, Venge P, Siew E, Ware LB, Ikizler A, Mertens PR (2011) The outcome of neutrophil gelatinase-associated lipocalin-positive subclinical acute kidney injury. J Am Coll Cardiol 57:1752-1761

11. Nickolas TL, Schmidt-Ott KM, Canetta P, Forster C, Singer E, Sise M, Elger A, Maarouf O, Sola-Del Valle DA, O'Rourke M, Sherman E, Lee P, Geara A, Imus P, Guddati A, Polland A, Rahman W, Elitok S, Malik N, Giglio J, El-Sayegh S, Devarajan P, Hebbar S, Saggi SJ, Hahn B, Kettritz R, Luft FC, Barasch J (2012) Diagnostic and prognostic stratification in the emergency department using urinary biomarkers of nephron damage. J Am Coll Cardiol 59:246-255

12. Kashani K, Al-Khafaji A, Ardiles T, Artigas A, Bagshaw SM, Bell M, Bihorac A, Birkhahn R, Cely CM, Chawla LS, Davison DL, Feldkamp T, Forni LG, Gong MN, Gunnerson KJ, Haase M, Hackett J, Honore PM, Hoste EA, JoannesBoyau O, Joannidis M, Kim P, Koyner JL, Laskowitz DT, Lissauer ME, Marx G, McCullough PA, Mullaney S, Ostermann M, Rimmele T, Shapiro NI, Shaw AD, Shi J, Sprague AM, Vincent J-L, Vinsonneau C, Wagner L, Walker MG, Wilkerson RG, Zacharowski K, Kellum JA (2013) Discovery and validation of cell cycle arrest biomarkers in human acute kidney injury. Crit Care 17:R25

13. Gomez H, Kellum JA (2016) Sepsis-induced acute kidney injury. Curr Opin Crit Care 22:546-553

14. Ronco C, Chawla LS (2016) Glomerular and tubular kidney stress test: new tools for a deeper evaluation of kidney function. Nephron 134:191-194

15. Wang E, Meier DJ, Sandoval RM, Von Hendy-Willson VE, Pressler BM, Bunch RM, Alloosh M, Sturek MS, Schwartz GJ, Molitoris BA (2012) A portable fiberoptic ratiometric fluorescence analyzer provides rapid point-ofcare determination of glomerular filtration rate in large animals. Kidney Int 81:112-117

16. Bagshaw SM, Uchino S, Bellomo R et al (2007) Septic acute kidney injury in critically ill patients: clinical characteristics and outcomes. Clin J Am Soc Nephrol 2:431-439

17. Bouchard J, Acharya A, Cerda J et al (2015) A prospective international multicenter study of AKI in the intensive care unit. Clin J Am Soc Nephrol 10:1324-1331

18. Angus DC, Linde-Zwirble WT, Lidicker J, Clermont G, Carcillo J, Pinsky MR (2001) Epidemiology of severe sepsis in the United States: analysis of incidence, outcome, and associated costs of care. Crit Care Med 29:1303-1310

19. Vincent JL, Sakr Y, Sprung CL et al (2006) Sepsis in European intensive care units: results of the SOAP study. Crit Care Med 34:344-353

20. Poukkanen $M$, Vaara ST, Pettila V et al (2013) Acute kidney injury in patients with severe sepsis in Finnish intensive care units. Acta Anaesthesiol Scand 57:863-872

21. Gordon AC, Mason AJ, Thirunavukkarasu N et al (2016) Effect of early vasopressin vs norepinephrine on kidney failure in patients with septic shock: the VANISH randomized clinical trial. JAMA 316:509-518 
22. Haase-Fielitz Al, Haase M, Bellomo R, Dragun D (2007) Genetic polymorphisms in sepsis- and cardiopulmonary bypass-associated acute kidney injury. Contrib Nephrol 156:75-91

23. Zhao B, Lu Q, Cheng Y, Belcher JM et al (2017) A genome-wide association study to identify single nucleotide polymorphisms for acute kidney injury. Am J Respir Crit Care Med 195:482-490

24. Kaukonen KM, Bailey M, Suzuki S, Pilcher D, Bellomo R (2014) Mortality related to severe sepsis and septic shock among critically ill patients in Australia and New Zealand, 2000-2012. JAMA 311:1308-1316

25. Wald R, McArthur E, Adhikari NK et al (2015) Changing incidence and outcomes following dialysis-requiring acute kidney injury among critically ill adults: a population-based cohort study. Am J Kidney Dis 65:870-877

26. Schrier RW, Wang W (2004) Acute renal failure and sepsis. N Engl J Med 351:159-169

27. Langenberg C, Wan L, Egi M et al (2006) Renal blood flow in experimental septic acute renal failure. Kidney Int 69:1996-2002

28. Di Giantomasso D, May CN, Bellomo R (2003) Vital organ blood flow during hyperdynamic sepsis. Chest 124:1053-1059

29. Langenberg C, Bellomo R, May C, Wan L, Egi M, Morgera S (2005) Renal blood flow in sepsis. Crit Care 9:R363-R374

30. Prowle JR, Molan MP, Henessy E, Bellomo R (2012) Measurement of renal blood flow by phase contrast magnetic resonance imaging during septic acute kidney injury: a pilot investigation. Crit Care Med 40:1768-1776

31. Verma SK, Molitoris BA (2015) Renal endothelial injury and microvascular dysfunction in acute kidney injury. Semin Nephrol 35:96-107

32. Post EH, Kellum JA, Bellomo R, Vincent J-L (2017) Renal perfusion in sepsis: from macro- to microcirculation. Kidney Int 91:45-60

33. Calzavacca P, Evans RG, Bailey M, Bellomo R, May CN (2015) Cortical and medullary tissue perfusion and oxygenation in experimental septic acute kidney injury. Crit Care Med 43:e431-e439

34. Lankadeva YR, Kosaka J, Evans RG, Bailey M, Bellomo R, May CN (2016) Intra-renal and urinary oxygenation during norepinephrine resuscitation in ovine septic acute kidney injury. Kidney Int 90:100-108

35. Casellas D, Mimran A (1979) Aglomerular pathways in intrarenal microvasculature of aged rats. Am J Anat 156:293-299

36. Dellepiane S, Marengo M, Cantaluppi V (2016) Detrimental cross-talk between sepsis and acute kidney injury: new pathogenic mechanisms, early biomarkers and targeted therapies. Crit Care 20:61

37. Mariano F, Cantaluppi V, Stella M et al (2008) Circulating plasma factors induce tubular and glomerular alterations in septic burns patients. Crit Care 12:R42

38. Doi K, Leelahavanichkul A, Yuen PST et al (2009) Animal models of sepsis and sepsis-induced kidney injury. J Clin Investig 119:2868-2878

39. Lerolle N, Nochy D, Guérot E et al (2010) Histopathology of septic shock induced acute kidney injury: apoptosis and leukocytic infiltration. Intensive Care Med 36:471-478

40. Takasu O, Gaut JP, Watanabe E et al (2013) Mechanisms of cardiac and renal dysfunction in patients dying of sepsis. Am J Resp Crit Care Med 187:509-517

41. Langenberg C, Gobe G, Hood S et al (2014) Renal histopathology during experimental septic acute kidney injury and recovery. Crit Care Med 42:e58-e67

42. Maiden MJ, Otto S, Brealey JK et al (2016) Structure and function of the kidney in septic shock. A prospective controlled experimental study. Am J Resp Crit Care Med 194:692-700

43. Basu RK, Zappitelli M, Brunner L, Wang Y, Wong HR, Chawla LS et al (2014) Derivation and validation of the renal angina index to improve the prediction of acute kidney injury in critically ill children. Kidney Int 85(3):659-667

44. Honore PM, Nguyen HB, Gong M, Chawla LS, Bagshaw SM, Artigas A et al (2016) Urinary tissue inhibitor of metalloproteinase-2 and insulin-like growth factor-binding protein 7 for risk stratification of acute kidney injury in patients with sepsis. Crit Care Med 44(10):1851-1860

45. Colpaert K, Hoste EA, Steurbaut K, Benoit D, Van Hoecke S, De Turck F et al (2012) Impact of real-time electronic alerting of acute kidney injury on therapeutic intervention and progression of RIFLE class. Crit Care Med 40(4):1164-1170

46. Bagshaw SM, Goldstein SL, Ronco C, Kellum JA, Group AC (2016) Acute kidney injury in the era of big data: the 15(th) Consensus Conference of the Acute Dialysis Quality Initiative (ADQI). Can J Kidney Health Dis 3:5
47. Lachance P, Villeneuve P, Wilson FP, Selby FM, Featherstone RM et al (2016) Impact of e-alert for detection of acute kidney injury on processes of care and outcomes: protocol for a systematic review and meta-analysis. BMJ Open 5:e011152

48. Goldstein SL, Mottes T, Simpson K, Barclay C, Muething S, Haslam DB et al (2016) A sustained quality improvement program reduces nephrotoxic medication-associated acute kidney injury. Kidney Int 90:212-221

49. Bagshaw SM, Lapinsky S, Dial S, Arabi Y, Dodek P, Wood G et al (2009) Acute kidney injury in septic shock: clinical outcomes and impact of duration of hypotension prior to initiation of antimicrobial therapy. Intensive Care Med 35:871-881

50. Kellum JA, Chawla LS, Keener C, Singbartl K, Palevsky PM, Pike FL et al (2016) The effects of alternative resuscitation strategies on acute kidney injury in patients with septic shock. Am J Respir Crit Care Med 193:281-287

51. Mouncey PR, Osborn TM, Power GS, Harrison DA, Sadique MZ, Grieve RD, Jahan R, Harvey SE, Bell D, Bion JF, Coats TJ, Singer M, Young JD, Rowan KM (2015) Trial of early, goal-directed resuscitation for septic shock. N Engl J Med 372:1301-1311

52. The ProCess Investigators (2014) A randomized trial of protocol-based care for early septic shock. N Engl J Med 370:1683-1693

53. Peake SL, Delaney A, Bailey M, Bellomo R, Cameron PA, Cooper DJ, Higgins AM, Holdgate A, Howe BD, Webb SA, Williams P (2014) Goaldirected resuscitation for patients with early septic shock. N Engl J Med 371:1496-1506

54. Gordon AC, Russell JA, Walley KR, Singer J, Ayers D, Storms MM et al (2016) The effects of vasopressin on acute kidney injury in septic shock. Intensive Care Med 36:83-91

55. Morelli A, Ricci Z, Bellomo R, Ronco C, Rocco M, Conti G et al (2005) Prophylactic fenoldopam for renal protection in sepsis: a randomized, double-blind, placebo-controlled pilot trial. Crit Care Med 33:2451-2456

56. Bellomo R, Cass A, Cole L, Finfer S, Gallagher M, Lee J, Lo S, McArthur C, McGuiness S, Norton R, Myburgh J, Scheinkestel C, Su S (2012) An observational study fluid balance and patient outcomes in the randomized evaluation of normal vs. augmented level of replacement therapy trial. Crit Care Med 40:1753-1760

57. Boyd JH, Forbes J, Nakada TA, Walley KR, Russell JA (2011) Fluid resuscitation in septic shock: a positive fluid balance and elevated central venous pressure are associated with increased mortality. Crit Care Med 39:259-265

58. Wiedemann HP, Wheeler AP, Bernard GR, Thompson BT, Hayden D, deBoisblanc B, Connors AF Jr, Hite RD, Harabin AL (2006) Comparison of two fluid-management strategies in acute lung injury. N Engl J Med 354:2564-2575

59. Bouchard J, Soroko SB, Chertow GM, Himmelfarb J, Ikizler TA, Paganini EP, Mehta RL (2009) Fluid accumulation, survival and recovery of kidney function in critically ill patients with acute kidney injury. Kidney Int 76:422-427

60. Hjortrup PB, Haase N, Bundgaard H, Thomsen SL, Winding R, Pettila V, Aaen A, Lodahl D, Berthelsen RE, Christensen H, Madsen MB, Winkel P, Wetterslev J, Perner A, CLASSIC Trial Group, Scandinavian Critical Care Trials Group (2016) Restricting volumes of resuscitation fluid in adults with septic shock after initial management: the CLASSIC randomised, parallelgroup, multicentre feasibility trial. Intensive Care Med 42:1695-1705

61. Lipscey M, Craig J, Suibiakto I et al (2015) Primary fluid bolus therapy for infection-associated hypotension in the emergency department. Crit Care Resusc 17:6-11

62. Lipscey M, Suibiakto I, Chiong J et al (2016) Secondary fluid bolus therapy for infection-associated hypotension. Crit Care Resusc 18:165-173

63. Bannard-Smith J, Alexander P, Glassford N et al (2015) Haemodynamic and biochemcial responses to fluid bolus therapy with human albumin solution, 4\% versus 20\% in critically ill adults. Crit Care Resusc 17:122-128

64. Yunos NM, Bellomo R, Glassford N, Sutcliffe H, Lam Q, Bailey M (2015) Chloride-liberal vs. chloride-restrictive intravenous fluid administration and acute kidney injury: an extended analysis. Intensive Care Med 41:257-264

65. Shaw AD, Raghunathan K, Peyerl FW, Munson SH, Paluszkiewicz SM, Schermer CR (2014) Association between intravenous chloride load during resuscitation and in-hospital mortality among patients with SIRS. Intensive Care Med 40:1897-1905 
66. Young P, Bailey M, Beasley R, Henderson S, Mackle D, McArthur C, McGuinness S, Mehrtens J, Myburgh J, Psirides A, Reddy S, Bellomo R, SPLIT Investigators, Anzics CTG (2015) Effect of a buffered crystalloid solution vs saline on acute kidney injury among patients in the intensive care unit: the SPLIT randomized clinical trial. JAMA 314:1701-1710

67. Semler MW, Wanderer JP, Ehrenfeld JM, Stollings JL, Self WH, Siew ED, Wang L, Byrne DW, Shaw AD, Bernard GR, Rice TW, SALT Investigators and the Pragmatic Critical Care Research Group (2016) Balanced crystalloids versus saline in the intensive care unit: the SALT randomized Trial. Am J Resp Crit Care Med. doi:10.1164/rccm.201607-1345OC

68. Finfer S, Bellomo R, Boyce N, French J, Myburgh J, Norton R et al (2004) A comparison of albumin and saline for fluid resuscitation in the intensive care unit. N Engl Med 350:2247-2256

69. Perner A, Haase N, Guttormsen AB, Tenhunen J, Klemenzson G, Aneman A, Madsen KR, Moller MH, Elkjaer JM, Poulsen LM, Bendtsen A, Winding R, Steensen M, Berezowicz P, Soe-Jensen P, Bestle M, Strand K, Wiis J, White JO, Thornberg KJ, Quist L, Nielsen J, Andersen LH, Holst LB, Thormar K, Kjaeldgaard AL, Fabritius ML, Mondrup F, Pott FC, Moller TP, Winkel P, Wetterslev J, 6S Trial Group, Scandinavian Critical Care Trials Group (2012) Hydroxyethyl starch 130/0.42 versus Ringer's acetate in severe sepsis. N Engl J Med 367:124-134

70. Pisano A, Landoni G, Bellomo R (2016) The risk of infusing gelatin? Diehard misconceptions and forgotten (or ignored) truths. Miner Anestesiol 82:1107-1114

71. Chawla LS, Busse L, Brasha-Mitchell E, Davison D, Honiq J, Alotaibi Z, Seneff MG (2014) Intravenous angiotensin II for the treatment of high-output shock (ATHOS trial): a pilot study. Crit Care 18:534

72. Myburgh JA, Higgins A, Jovanovska A, Lipman J, Ramakrishnan N, Santamaria J (2008) A comparison of epinephrine and norepinephrine in critically ill patients. Intensive Care Med 34:2226-2234

73. De Backer D, Aldecoa C, Njimi H, Vincent J-L (2012) Dopamine versus norepinephrine in the treatment of septic shock: a meta-analysis. Crit Care Med 40:725-730

74. Asfar P, Meziani F, Hamel JE et al (2014) High versus low blood pressure target in patients with septic shock. N Engl J Med 370:1583-1593

75. Payen D, Mateo J, Cavaillon JM, Fraisse F, Floriot C, Vicaut E (2009) Impact of continuous venovenous hemofiltration on organ failure during the early phase of severe sepsis: a randomized controlled trial. Crit Care Med 37:803-810

76. Zhang P, Yang Y, Lv R, Zhang Y, Xie W, Chen J (2012) Effect of the intensity of continuous renal replacement therapy in patients with sepsis and acute kidney injury: a single-center randomized clinical trial. Nephrol Dial Transpl 27:967-973

77. Joannes-Boyau O, Honore PM, Perez P, Bagshaw SM, Grand H, Canivet JL, Dewitte A, Flamens C, Pujol W, Grandoulier AS et al (2013) High-volume versus standard-volume haemofiltration for septic shock patients with acute kidney injury (IVOIRE study): a multicentre randomized controlled trial. Intensive Care Med 39:1535-1546
78. Park JT, Lee H, Kee YK, Park S, Oh HJ, Han SH, Joo KW, Lim CS, Kim YS, Kang SW et al (2016) High-dose versus conventional-dose continuous venovenous hemodiafiltration and patient and kidney survival and cytokine removal in sepsis-associated acute kidney injury: a randomized controlled trial. Am J Kidney Dis 68:599-608

79. Zarbock A, Kellum JA, Schmidt C, Van Aken H, Wempe C, Pavenstadt H, Boanta A, Gerss J, Meersch M (2016) Effect of early vs delayed initiation of renal replacement therapy on mortality in critically ill patients with acute kidney injury: the ELAIN randomized clinical trial. JAMA 315:2190-2199

80. Gaudry S, Hajage D, Schortgen F, Martin-Lefevre L, Pons B, Boulet E, Boyer A, Chevrel G, Lerolle N, Carpentier D et al (2016) Initiation strategies for renal-replacement therapy in the intensive care unit. N Engl J Med 375:122-133

81. RENAL Replacement Therapy Study Investigators, Bellomo R, Cass A, Cole L, Finfer S, Gallagher M, Lo S, McArthur C, McGuinness S, Myburgh J et al (2009) Intensity of continuous renal-replacement therapy in critically ill patients. N Engl J Med 361:1627-1638

82. Palevsky PM, Zhang JH, O'Connor TZ, Chertow GM, Crowley ST, Choudhury D, Finkel K, Kellum JA, Paganini E, Schein RM et al (2008) Intensity of renal support in critically ill patients with acute kidney injury. N Engl J Med 359:7-20

83. Roberts DM, Liu X, Roberts JA, Nair P, Cole L, Roberts MS, Lipman J, Bellomo R (2015) A multicenter study on the effect of continuous hemodiafiltration intensity on antibiotic pharmacokinetics. Crit Care 13(19):84

84. Caironi P, Tognoni G, Masson S et al (2014) Albumin replacement in patients with severe sepsis or septic shock. N Engl J Med 370:1412-1421

85. Peters E, Mehta RL, Murray PT, Hummel J, Joannidis M, Kellum JA, Arend J, Pikkers $P$ (2016) Study protocol for a multicentre randomised controlled trial: safety, tolerability, efficacy, and quality of life of a human recombinant alkaline phosphatase in patients with sepsis-associated acute kidney injury. BMJ Open 6:e012371

86. Chawla LS, Russell JA, Bagshaw SM et al (2017) Angiotensin for the treatment of high output shock 3 (ATHOS-3): a study protocol for a phase 3, double-blind, randomized controlled trial. Crit Care Resusc 2017 19:43-49.

87. Venot M, Weis L, Clec'h C, Darmon M, Allaouchiche B, Goldgran-Toledano D, Garrouste-Orgeas M, Adrie C, Timsit JF, Azoulay E (2015) Acute kidney injury in severe sepsis and septic shock in patients with and without diabetes mellitus: a multicenter study. PLoS One 10:e0127411

88. Wald R, Quinn RR, Adhikari NK et al (2012) Risk of chronic dialysis and death following acute kidney injury. Am J Med 125:585-593

89. Pickkers P, Ostermann M, Joannidis M, Zarbock A, Hoste E, Bellomo R, Prowle J, Darmon M, Bonventre JV, Forni L, Bagshaw SM, Schetz M (2017) The intensive care medicine agenda on acute kidney injury. Intensive Care Med. doi:10.1007/s00134-017-4687-2 